\title{
Preliminary study of simple methods to get the average speed using a smartphone's light sensor
}

\author{
Ea Cahya Septia Mahen ${ }^{1, *}$, Seni Susanti $^{1}$, Bebeh Wahid Nuryadin ${ }^{2}$, and Ade Yeti Nuryantini ${ }^{1}$ \\ ${ }^{1}$ UIN Sunan Gunung Djati Bandung, Physics Education Departement, Bandung, Indonesia \\ ${ }^{2}$ UIN Sunan Gunung Djati Bandung, Physics Departement, Bandung, Indonesia
}

\begin{abstract}
This paper reports on the result of a preliminary study of utilization of a smartphone ambient light sensor for get the average speeds of motion along a straight line based on experiments. We attach a smartphone to a dynamics train that travels across multiple light sources where the distance is already set. The main source of this experiment is obtained from the luminosity curve obtained from free android applications. From the curve, we can get position information against time. So from the data we can get the value of average speed. Then the use of the smartphone light sensor in physics experiments can be done easily and fun.
\end{abstract}

\section{Introduction}

Mobile devices such as smartphones and tablets are part of the daily life of many young people in recent years, and in many cases even for kids [1]. Besides its main functions to perform communications, the smartphone is equipped with advanced features and functionality such as built-in camera, audio/video playback and recording, play games, play video, display photos, send/ receive email, social media, wireless internet, navigation, and much more [2]. smartphone is also equipped with several sensors, such as accelerometer, gyroscope, magnetometer, proximity sensor, light sensor, and in several higher-end phones includes barometer, thermometer, air humidity sensor, pedometer, and other as shown in Figure 1.

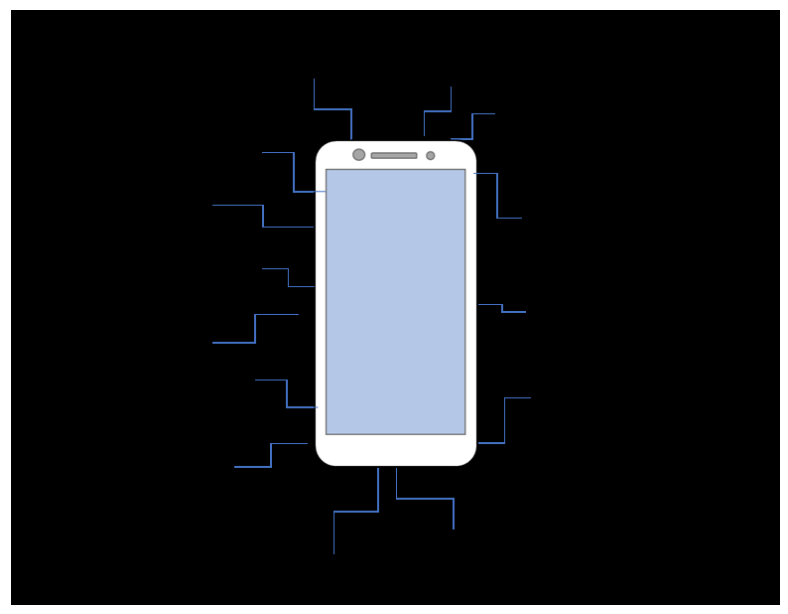

Fig. 1. Some sensors are embedded in the smartphone.

Recently, there are many published works explaining physics experiments that can be performed using sensor of smartphones. Smartphone pressure sensors can be used to measure vertical velocities [3], and analysing Stevin's law [4]. Accelerometer and Gyroscope can be used to analyzing simple pendulum [5], study of two-dimensional oscillations [6], analysing free fall [7], introduction to the concepts of acceleration and deceleration [8], Investigation of the rolling motion of a hollow cylinder [9], Investigation of kinetic friction [10], analyse free and damped oscillations [11] and coupled oscillations [12]. Magnetometer can be used to measure the magnetic field of small magnets[13], and magnetic field due to electrical current in straight and loop wires[14].

Sans et al [15] demoralized the use of the smartphone light sensor to analyse a system of coupled oscillators. While Kapucu [16] utilizes light sensors to obtain average speeds by combining the physics knowledge of optics and kinematics. In this paper, we will present a preliminary study of a simpler method of obtaining average grade grades using light sensors without having to understand more deeply about optical concepts.

\section{Experimental Method}

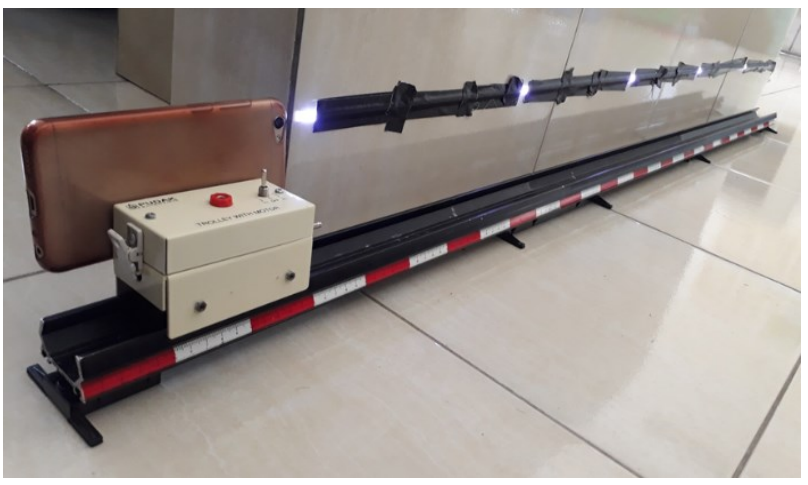

Fig. 2. Set-up experiment

\footnotetext{
* Corresponding author: ea.cahya@uinsgd,.ac.id
} 
Figure 2 shows the composition of the equipment used in the study. Equipment used include: smartphone (Vivo), trolley or motor dynamics train, rail, LED strip rails, solifies and double tip. In the experiments, the application of the light meter (Light meter on the physics tool Box) as shown in Figure 3 is preinstalled. Smartphones are affixed to the dynamics trains using double-sided tape with light sensor in a position facing the light source. Furthermore, the dynamics train is moved through a light source derived from the LED strip whose distance between the LEDs is made fixed $10 \mathrm{~cm}$.

As the dynamics train moves past the LED arrangement, it captures the light intensity every time. Some peaks of illuminance when the light sensor on the smartphone right past the LED will be clamped on the physics toolbox ligh meter application. Since the distance between the previous LEDs is predetermined, then we can get the data of train trains dynamics through the light source. From this information we can determine to make the displacement curve over time so that the average speed can be determined.

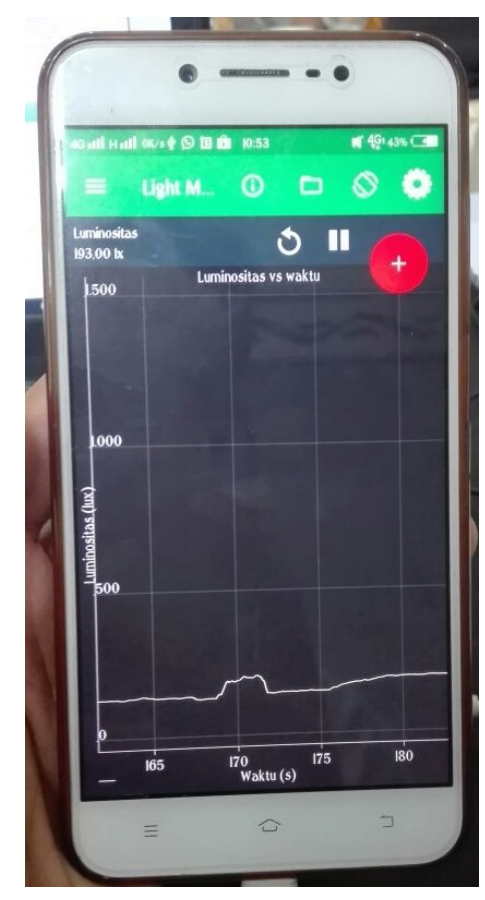

Fig. 3. Light meter display on physics tool box.

\section{Result and Discussion}

In this preliminary study we obtained light intensity data recorded using the software lighmeter physiscs toolbox as shown in Figure 4. In the Figure we can see some peaks of light intensity. The peak of light intensity is obtained when the smartphone's light sensor is right in front of the light source. This is based on the illuminance $E v$ and luminous intensity $I v$ for a point light source $E v=I v / \mathrm{d}^{2}$ [17]. The value of illuminance (Ev) is inversely proportional to the distance $d$ of the squared distance. So, the greatest value must be when the positioning of the smartphone's light sensor is right in front of the light source which is the closest one. The peak illuminance of each lamp is not the same because the light intensity (iv) of each source is different.

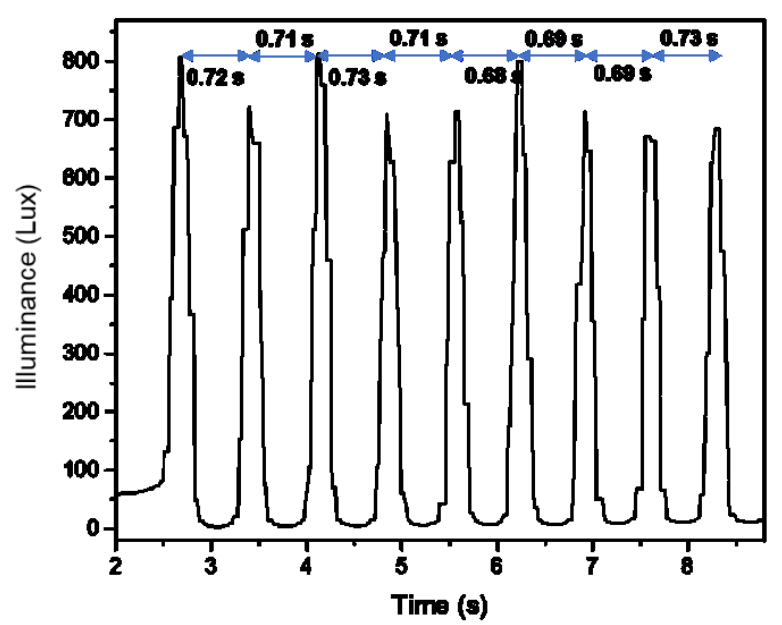

Fig. 4. Curve of light intensity of smartphone.

From Figure 4 we know the time range that a smartphone passes through one light source to another. The time range traversed is relatively close to the average value of $0.71 \mathrm{~s}$. From the information shown in Figure 2 we can create the vs. time displacement curve because the previous distance between the light sources is already set $10 \mathrm{~cm}$.

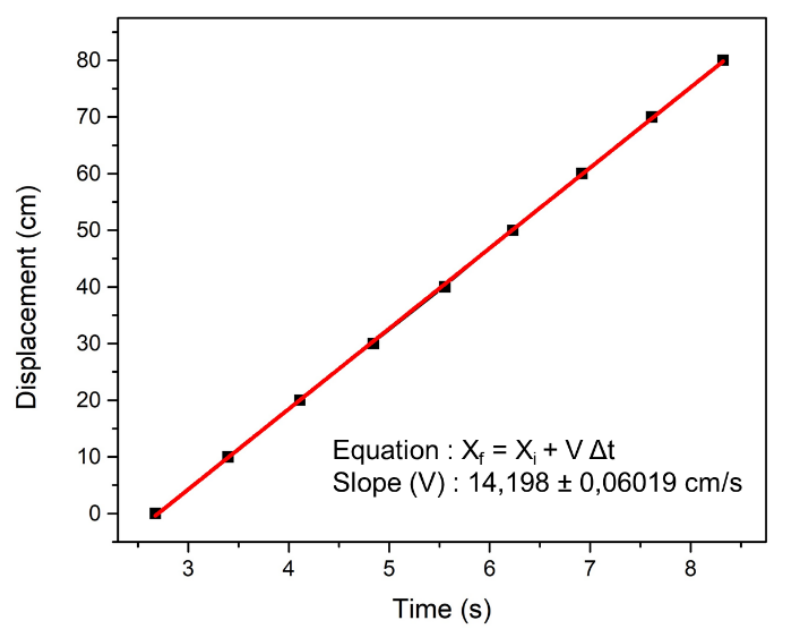

Fig. 5. Curve of displacement versus time.

Figure 5 shows the displacement curve. The lines indicated by the curve form almost straight lines. Using linear fittings, we find the equation $\mathrm{xf}=\mathrm{xi}+\mathrm{vt}$. The value of the slope of the displacement curve is the average speed [18-20]. From the graph we get the average speed is $14.198 \pm 0.0601 \mathrm{~cm} / \mathrm{s}$. To confirm this, we also compare the average speed score every $10 \mathrm{~cm}$ distance traveled by smartphone using ratio of the displacement $\Delta \mathrm{x}$ that occurs during a particular time interval $\Delta \mathrm{t}$ to that interval [18]: $v_{\text {avg }}=\Delta \mathrm{x} / \Delta \mathrm{t}=\left(\mathrm{x}_{\mathrm{f}}-\mathrm{X}_{\mathrm{i}}\right) /\left(\mathrm{t}_{\mathrm{f}}-\mathrm{t}_{\mathrm{i}}\right)$. 
Table 1. Value of average speeds.

\begin{tabular}{|c|c|c|c|c|c|}
\hline No & $\mathrm{t}(\mathrm{s})$ & $\begin{array}{c}\mathrm{x} \\
(\mathrm{cm})\end{array}$ & $\Delta \mathrm{t}(\mathrm{s})$ & $\begin{array}{c}\Delta \mathrm{x} \\
(\mathrm{cm})\end{array}$ & $\begin{array}{c}\mathrm{V}_{\text {average }} \\
(\mathrm{cm} / \mathrm{s})\end{array}$ \\
\hline 1 & 2,673 & 0 & & & \\
\hline 2 & 3,398 & 10 & 0,725 & 10 & 13,793 \\
\hline 3 & 4,111 & 20 & 0,713 & 10 & 14,025 \\
\hline 4 & 4,843 & 30 & 0,732 & 10 & 13,661 \\
\hline 5 & 5,556 & 40 & 0,713 & 10 & 14,025 \\
\hline 6 & 6,232 & 50 & 0,676 & 10 & 14,793 \\
\hline 7 & 6,92 & 60 & 0,688 & 10 & 14,535 \\
\hline 8 & 7,612 & 70 & 0,692 & 10 & 14,451 \\
\hline 9 & 8,324 & 80 & 0,712 & 10 & 14,045 \\
\hline
\end{tabular}

The average speeds of every $10 \mathrm{~cm}$ shown in Table 1 is likely to be close to and close to the value of $14.198 \mathrm{~cm}$ obtained from the linear fitting value of the displacement curve. From the table, it is seen that the average speed has slightly changed up and down. This can be caused by several things such as obstacles in the rail path through which causing the movement of the train dynamics slightly inhibited.

\section{Conclusion}

We have successfully learned about the other benefits of the smartphone light sensor for use in experiments to determine the average speed. The experimental results show the light sensor can capture time data driven smartphone along the train dynamics through the light source. From these data, we can get information on data displacement versus time. From the data can be determined the average speed rating. So that the smartphone light sensor with the appropriate application can be used as a cheap and easy to use equipment to get the average moving average value of the object.

This work was supported by a research grant from UIN Sunan Gunung Djati Bandung, the Ministry of Religious Affairs, Republic of Indonesia

\section{References}

1. M. Kleinemeier, Smartphones in Science Teaching (iStage2). Berlin: Science on Stage Deutschland e.V., (2014).

2. M. Sarwar and T. R. Soomro, "Impact of Smartphone' s on Soci ety," Eur. J. Sci. Res., vol. 98, no. 2, pp. 216-226, (2013).

3. M. Monteiro and A. C. Marti, "Using smartphone pressure sensors to measure vertical velocities of elevators , stairways , and drones," Phys. Educ., vol. 52, pp. 1-11, (2017).

4. S. Macchia, "Analyzing Stevin's law with the smartphone barometer," Phys. Teach., vol. 54, p. 373, (2016).

5. P. Vogt and J. Kuhn, "Analyzing simple pendulum phenomena with a smartphone acceleration sensor,"
Phys. Teach., vol. 50, pp. 439-440, (2012).

6. L. Tuset-sanchis and J. C. Castro-palacio, "The study of two-dimensional oscillations using a smartphone acceleration sensor: example of Lissajous curves," Phys. Educ., vol. 50, no. 5, pp. 580-586, (2015).

7. P. Vogt and J. Kuhn, "Analyzing free fall with a smartphone acceleration sensor," Phys. Teach., vol. 50, pp. 182-183, (2012).

8. M. Oprea and C. Miron, "Mobile phones in the modern teaching of physics," Rom. Reports Phys., vol. 66, no. 4, (2014).

9. C. Puttharugsa, S. Khemmani, P. Utayarat, and W. Luangtip, "Investigation of the rolling motion of a hollow cylinder using a smartphone," Eur. J. Phys., vol. 37, no. 5, pp. 1-10, (2016).

10. C. Baldock and R. Johnson, "Investigation of kinetic friction using an iPhone," Phys. Educ., vol. 51, pp. 1-6, (2016).

11. J. Carlos Castro-Palacio, L. Velázquez-Abad, M. H. Giménez, and J. a. Monsoriu, "Using a mobile phone acceleration sensor in physics experiments on free and damped harmonic oscillations," Am. J. Phys., vol. 81, no. 6, p. 472, (2013).

12. J. C. Castro-Palacio, L. Velázquez-Abad, F. Giménez, and J. a Monsoriu, "A quantitative analysis of coupled oscillations using mobile accelerometer sensors," Eur. J. Phys., vol. 34, no. 3, pp. 737-744, (2013).

13. E. Arribas, I. Escobar, and C. P. Suarez, "Measurement of the magnetic fi eld of small magnets with a smartphone: a very economical laboratory practice for introductory physics courses," Eur. J. Phys., vol. 36, no. 6, pp. 1-11, (2015).

14. R. D. Septianto, D. Suhendra, and F. Iskandar, "Utilisation of the magnetic sensor in a smartphone for facile magnetostatics experiment : magnetic field due to electrical current in straight and loop wires," Phys. Educ., vol. 52, pp. 1-7, (2017).

15. J. A. Sans, F. J. Manjon, A. L. J. Pereira, GomezTejedor J A, and J. Monsoriu, "Oscillations studied with the smartphone ambient light sensor," Eur. J. Phys., vol. 1349, pp. 1349-1354, (2013).

16. S. Kapucu, "Finding the average speed of a lightemitting toy car with a smartphone light sensor," Phys. Educ., vol. 52, no. 4, p. 45001, Jul. (2017).

17. A. E. Taylor, Illumination Fundamentals. New York: Lighting Research Center, Rensselaer Polytechnic Institute, Troy, (2000).

18. Halliday and Resnick, Fundamental of Physics 10th Edition, vol. 1. (2015).

19. P. a. Tipler and G. Mosca, Physics for Scientists and Engineers. (2009).

20. H. Young and R. Freedman, University physics with modern physics. (2007). 